\title{
Quasi real-time electromagnetic and greenhouse gases monitoring station at Seymour - Marambio Island, Antarctica
}

\author{
Juan Manuel Solano $^{1 *}$, Carlos Alberto Vargas ${ }^{1}$, Adriana Maria Gulisano ${ }^{2}$ \\ ${ }^{1}$ Departamento de Geociencias, Universidad Nacional de Colombia \\ ${ }^{2}$ Instituto Antártico Argentino, Dirección Nacional del Antártico, CONICET - \\ Universidad de Buenos Aires, Instituto de Astronomía y Física del Espacio (IAFE), \\ Universidad de Buenos Aires, Facultad de Ciencias Exactas y Naturales, Departamento \\ de Física
}

\begin{abstract}
A new permanent geophysical station was installed in the Seymour-Marambio Island, Antarctica, for monitoring electromagnetic, $\mathrm{CO}_{2}$, and $\mathrm{CH}_{4}$ gas signals. Those signals require specialized low noise instruments and the survey shall be carried out in places far away from cultural noise, such as populated human settlements. The most suitable place would be near the Earth's poles, where noise is the lowest possible. To measure these variables, the Geophysical Instrumentation Laboratory (Laboratorio de Instrumentación Geofísica - LIG) of the Universidad Nacional de Colombia, in a partnership with the Instituto Antártico Argentino (IAA) under the Argentinean National Antarctic Direction (Dirección Nacional del Antártico - DNA), deployed the COCOAonMEAT project, oriented to design, built and install a low-cost station with time synchronization via GPS and data transmission in almost real-time. Since January 2020, the project monitors continuously (24/7) seven variables: three magnetic components, two electric dipoles, methane $\left(\mathrm{CH}_{4}\right)$, and carbon dioxide $\left(\mathrm{CO}_{2}\right)$ gas. Due to operative facilities and its low electromagnetic noise, the place chosen for its installation was the Argentinean Marambio Scientific Base in the Antarctic Peninsula, with the Multidisciplinary Antarctic Laboratory's collaboration (Laboratorio Multidisciplinario Antártico en la Base Marambio - LAMBI). This station provides valuable information on electromagnetic signals and greenhouse gases related to regional tectonic activity and local perturbations associated with global climate change.
\end{abstract}

Key words: electromagnetic field, magnetotellurics, Antarctic, Marambio-Seymour Island, tectonics, climate change, real-time monitoring

DOI: $10.5817 / C P R 2021-1-1$

Received January 17, 2021, accepted May 20, 2021.

*Corresponding author: Juan M. Solano <jmsolanof@unal.edu.co>

Acknowledgements: We are grateful to the Geophysics Group and the Geosciences Department of the Universidad Nacional de Colombia (National University of Colombia) for their support and insights. We would like to acknowledge all the help provided by the Argentinean Antarctic Institute (IAA - DNA) and the Argentinean Air Force (Fuerza Aérea Argentina - FAA) staff on Marambio Base, to Alexander Casallas and the Multidisciplinary Antarctic Laboratory (Laboratorio Multidisciplinario Antártico en la Base Marambio - LAMBI) crew: Sebastián, Hernán, Luciano, Marcelo, and now Daniel and Guillermo. Special thanks to Nury and her family for their support. 


\section{Introduction}

Earth's magnetic field and its consequent generated electric field on the soil provide valuable information about the inner Earth's structure, as shown by geophysical methods like geoelectric, magnetometry, and magnetotelluric - MT (Erkan 2008). The last one has gain popularity in the previous decades due to its low costbenefit ratio. Moreover, surveys require a relatively short duration (1-48 hours) with minimal impact on the soil (Simpson and Bahr 2005).

The valuable information obtained by the MT image allows subsurface resistivity images, being possible to discern from superficial phenomena such as the presence of water or underground ore deposits to deep structures such as the lithosphereasthenosphere boundary - LAB (CorboCamargo et al. 2013) or the Curie Point Depth (loss of the magnetic properties of minerals as a response to the thermal structure of the lithosphere)(Afshar et al. 2017). The MT method uses natural geomagnetic field variations on the ionosphere and lightning storms and consequent orthogonal electric field surface signals to establish the subsurface resistivity and map structures up to $600 \mathrm{~km}$ depending on sampling and survey duration (Simpson and Bahr 2005).

The two below-specified Latinamerican institutions have joined to evaluate temporal changes of apparent resistivity estimated by MT method. The Geophysical Instrumentation Laboratory (Laboratorio de Instrumentación Geofísica - LIG) of the National University of Colombia (Universidad Nacional de Colombia) has been active for more than 13 years in testing and installing a variety of equipment for geophysical surveys, especially seismological, magnetic and electrical instruments. The LIG receives signals from the National University Seismological Network (Red Sismológica de la Universidad Nacional de Colombia - RSUNAL). Current- ly, it has eight seismological stations with broadband and short-period seismic sensors, three of them are multiparametric (i.e. associated with magnetic and electric field sensors) completing a total of 8 channels per station. All the data acquired is sent near real-time to a computer server in Bogotá (Solano Fino 2017, Vargas et al. 2018). On the other hand, the National Antarctic Direction (Dirección Antártica Nacional - DNA) carries out the programming, planning, coordination, direction, control, and dissemination of the Argentine Antarctic activity ([1] - Ministerio de Relaciones Exteriores, 2019). Joining the LIG and DNA lead the project called COCOAonMEAT (Cooperation Colombian -Argentinean on Magneto - Electric Anomalies in Tectonics). Its primary aim is to detect electromagnetic or gas signals before tectonic or magmatic events happen.

There are several hypotheses on how those signals can be tectonically associated. The VAN team proposes seismic electric signals (SES) potentially detectable before earthquakes and represented by changes on the ground electric field from minutes to several hours (Varotsos et al. 2002, 2006, 2013). Several authors have brought an explanation that different frequency bands incorporated in the SES can be related to the magneto-hydrodynamic effect, piezomagnetic effect, electrokinetic effect, among others (Freund 2011, Petraki et al. 2015).

The Marambio Base, built in 1969, is an important Argentine Antarctic scientific base operated by the Argentinean Air Force (Fuerza Aérea Argentina - FAA). Fig. 1 shows the location of SeymourMarambio Island and the base at the north of it. Its soil is mostly permafrost desert with extremely little vegetation (some algae and mosses). Its fauna on land is restricted to birds such as skuas and a colony of Adélie penguins ([2] - Ministerio de Relaciones Exteriores, 2018) - Fore 
review see (Montalti and Soave 2002). The penguin colony is a restricted area located on SE coast of Seymour Island (Emslie et al. 2018).

\section{Material and Methods}

The signal coupling and recording device of the permanent geophysical station has two acquisition systems fed through a high-efficiency DC-DC converter from $12 \mathrm{~V}$ to $5 \mathrm{~V}$, each one composed of:

- Raspberry Pi 3 B+ (CPU)

- ADC (24 bit, up to 4 differential channels)

- GPS with antenna

There are two independent acquisition systems. Each one was assigned a different name: MRB3 and MRB4, belonging to the A0 network. This information is relevant for external users that need to access the recorded datasets.

The sensors used for magnetic and electric field measurement are a Bartington Mag648L triaxial magnetometer with low noise and range of $\pm 60 \mu \mathrm{T}$ ([3] - Bartington Instruments, 2015) and four copper ground pole electrodes $70 \mathrm{~cm}$ each. The magnetometer was buried in a $75 \mathrm{~cm}$-deep hole to avoid rapid fluctuations in surface temperature with the three axes (components) oriented north-south, east-west, and vertically following the right-hand convention. In comparison, the electrodes were installed at a depth of $80 \mathrm{~cm}$, with their upper connection protected by silicone to prevent corrosion. Each electrode was connected to the acquisition system with a $1.2 \mathrm{~cm}$ diameter copper cable protected by an extreme temperature-resistant polymer. The arrangement of the four electrodes that make up the two dipoles N-S (124 m) and E-W $(80.6 \mathrm{~m})$ is presented in Fig. 1.

Carbon dioxide $\left(\mathrm{CO}_{2}\right)$ and methane $\left(\mathrm{CH}_{4}\right)$ measurements are made with MG811 and MQ-4 sensors, whose working range is 0 to $5 \mathrm{~V}$, with a sensitivity of 350 to
$10,000 \mathrm{ppm}$ for the MG811 and 300 to $10,000 \mathrm{ppm}$ for the MQ-4. The gas sensors were installed in a $\mathrm{J}$-inverted structure made with PVC pipes to protect it and guarantee a differential pressure, allowing air circulation through the sensor. An external fiberglass box with an internal polyethylene foam lining for thermal insulation protects an interior isolated case, as well as connections, battery, and the power regulator. One hole was made in the lower corner of the box for entering the cables, which was also waterproofed with silicone. The acquisition system, sensors, and protection case are shown in Fig. 2. The information acquired by the eight channels system is shown in Table 1.

Due to operative facilities and its low electromagnetic noise, the permanent geophysical station was installed near the Multidisciplinary Antarctic Laboratory's collaboration (Laboratorio Multidisciplinario Antártico en la Base Marambio - LAMBI). The LAMBI provides continuous electrical power that feeds a $12 \mathrm{~V}-20 \mathrm{Ah}$ battery backup through a regulator to power the acquisition system.

Everything is controlled using Python language and existing libraries (acquisition, time synchronization, and communication modules), making it robust and scalable. The information acquired by the station in the LAMBI is sent every minute via FTP to the server located in the LIG, located in the Department of Geosciences of the National University of Colombia (Universidad Nacional de Colombia) at Bogotá for storage and provide to external users that request datasets. 

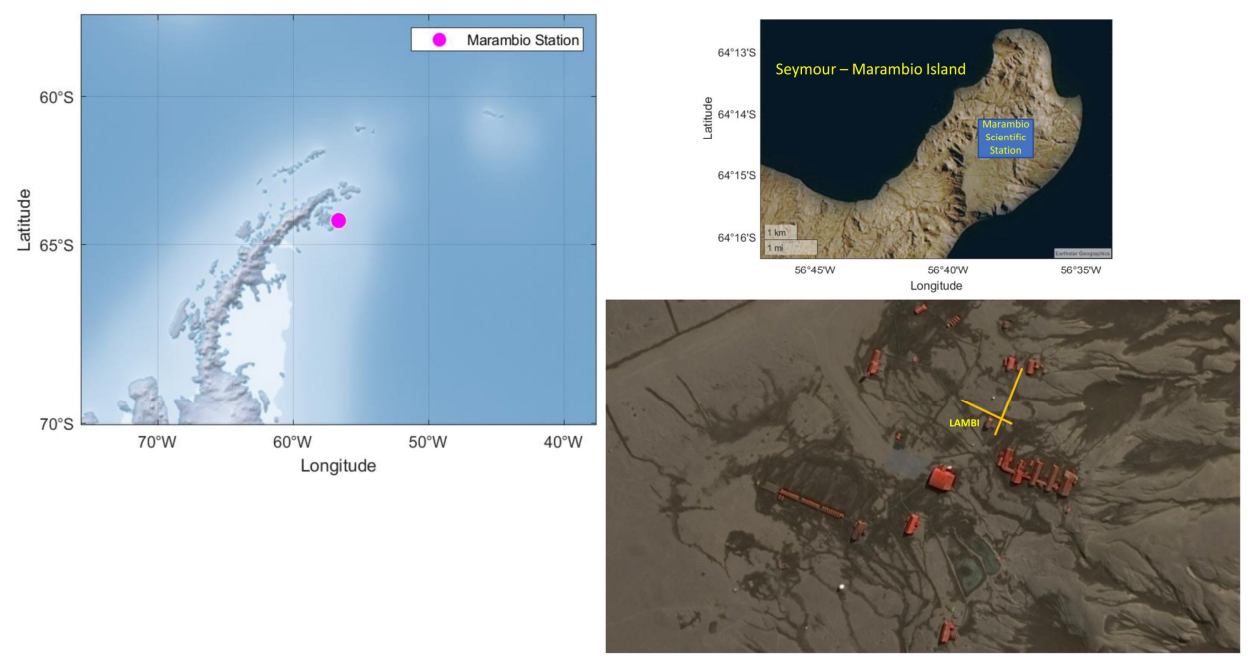

Fig. 1. Marambio Station and Seymour-Marambio Island location on the Antarctic Peninsula, permanent geophysical station location back to the LAMBI building on the Base and North-South and East-West dipoles (yellow lines).

The algorithm used for the systematic analyses of the datasets collected is being updated constantly. The MT method implies a quotient between electric and magnetic horizontal orthogonal components (i.e. N-S magnetic and $\mathrm{E}-\mathrm{W}$ electric signals) in the frequency domain on overlapping time windows over a defined period; fastest and more efficient ways to obtain this quotient and the following values are improved frequently. The central issue is mapping apparent resistivity anomalies on the subsurface with depth being a function of both the computed resistivity and the chosen period (for details of the procedure, see e.g. Simpson and Bahr 2005); these estimations shall be correlated with energetic tectonic or magmatic events and discarding any no-tectonomagmatic electromagnetic perturbation using the high latitude Kp-index (see e.g. Rangarajan and Iyemori 1997).

\begin{tabular}{|c|c|c|c|}
\hline Channels & Nomenclature & Signal & Sensor \\
\hline 1 & A0.MRB3.02.HFN & N-S magnetic field & Mag648L \\
\hline 2 & A0.MRB3.02.HFE & E-W magnetic field & Mag648L \\
\hline 3 & A0.MRB3.02.HFZ & Z magnetic field & Mag648L \\
\hline 4 & A0.MRB3.03.CO2 & Carbon dioxide & MG811 \\
\hline 5 & A0.MRB4.01.HQN & N-S electric field & Cupper electrode dipole \\
\hline 6 & A0.MRB4.01.HQE & E-W electric field & Cupper electrode dipole \\
\hline 7 & A0.MRB4.03.CH4 & Methane & MQ-4 \\
\hline
\end{tabular}

Table 1. Nomenclature of each variable acquired by the Permanent Geophysical Station of the COCOAonMEAT project. 


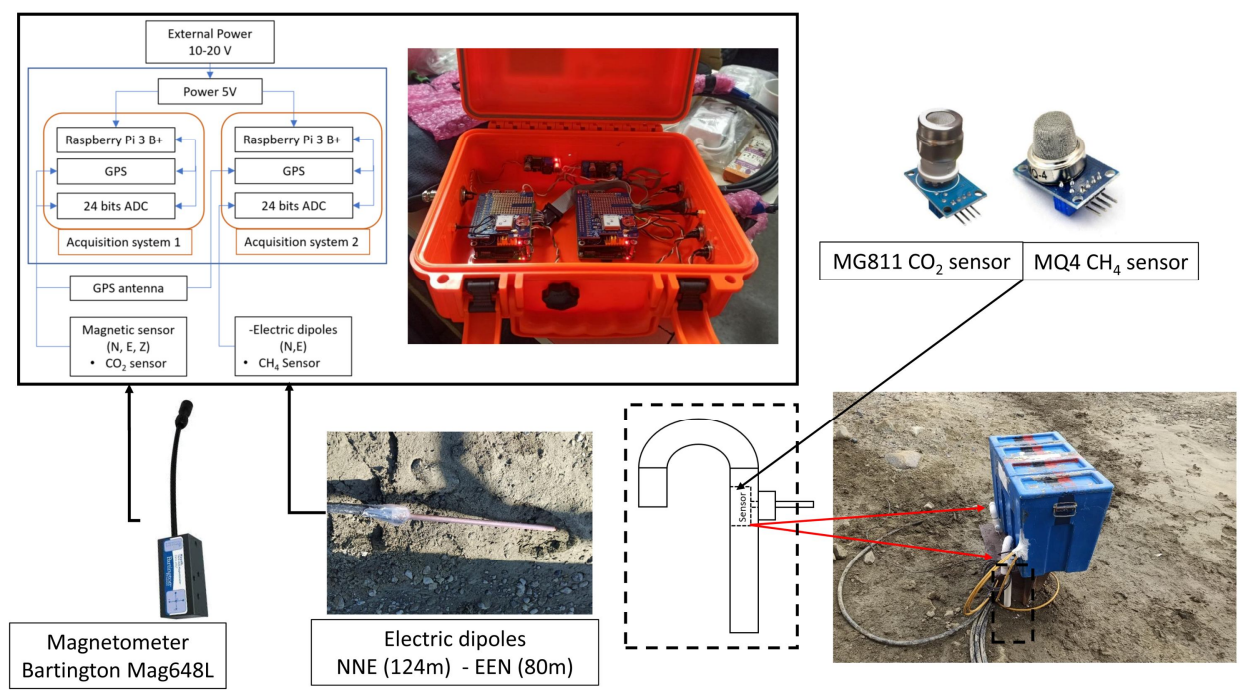

Fig. 2. Multiparametric Geophysical Permanent Station in the Seymour-Marambio Island. Upper left: Block diagram and acquisition system picture; upper right: MG811 and MQ4 gas sensors used; down from left to right: Mag648L magnetometer, copper electrode, PVC J-inverted structure for gas sensors, and external protection box (blue).

\section{Results, Discussion and Conclusions}

The international collaborative COCOA onMEAT project currently provides valuable data on the electromagnetic field and $\mathrm{CO}_{2}$ and $\mathrm{CH}_{4}$ gases. Earthquake precursor signals have been discussed over a century, but recently the magnetotelluric (MT) approach is at stake. Fig. 3 shows the subsurface apparent resistivity map over 14 days in Seymour-Marambio Island, obtained with the installed station and orthogonal electric and magnetic channels, as is suggested by the MT method. It also includes seismic events more significant than Mw4.5 obtained from the USGS Cata$\log$ ([4]-USGS, 2021), most of them from the Shetland Plate at around $230 \mathrm{~km}$. Fig. 3 also includes the high latitude $\mathrm{Kp}$-index for geomagnetic storms available on the NOAA web page ([5]-National Oceanic and
Atmospheric Administration, 2021) to disregard this source of noise. The anomaly map in the middle shows the resistivity percentage variance, which is useful for determining the smallest changes. After August $29^{\text {th }}, 2020$, some resistivity anomalies are detected, and several seismic events occur in the region. The top of the apparent resistivity map and the anomaly map shows a stable limit of low resistivity at $<200 \mathrm{~m}$, probably related to the permafrost layer over the sea level. Finally, the $\mathrm{CO}_{2}$ and $\mathrm{CH}_{4}$ gas measurements show a rapid peak by the end of August $29^{\text {th }}$, 2020 , which is being analyzed in the frame of hypotheses of the earthquake cycle (Chen et al. 2018, Lobkovsky 2020, Yue 2013). 

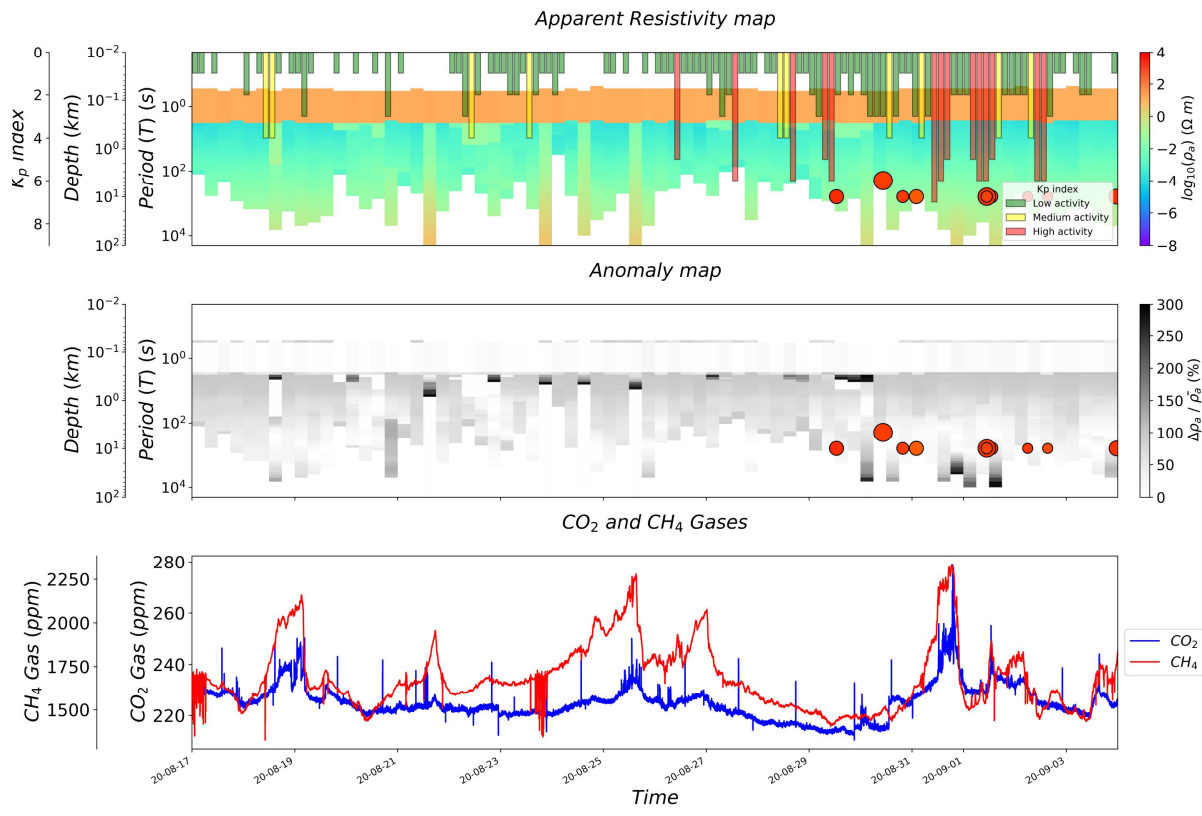

Fig. 3. Magnetotelluric apparent resistivity map and anomaly map from august $31^{\text {st }}$ to September $3^{\text {rd }}, 2020$, including near seismic events and geomagnetic storms $\mathrm{Kp}-$ index, and $\mathrm{CO}_{2}$ and $\mathrm{CH}_{4}$ gases measurements in parts per million ( $\mathrm{ppm}$ ). Notice the anomaly around august $29^{\text {th }}$, the gases peak, and the subsequent events.

Hence, robust analyses would be required to establish trusty patterns for adequately describing geophysical precursor occurrences. This monitoring system based on electromagnetic signals and greenhouse gases will understand the tectonic behavior of some continental margin regions. So far, we have seen similar behavior in the central region of Colombia with a resistivity anomaly previous to an M6.2 event at a $110 \mathrm{~km}$ distance from the station (Vargas et al. 2021). We intend to collect robust datasets to describe it as a global phenomenon that will require other stations in the world, but now we are starting with these two regions.

\section{References}

Afshar, A., Norouzi, G. H., Moradzadeh, A., Riahi, M. A. and Porkhial, S. (2017): Curie Point Depth, Geothermal Gradient and Heat-Flow Estimation and Geothermal Anomaly Exploration from Integrated Analysis of Aeromagnetic and Gravity Data on the Sabalan Area, NW Iran. Pure and Applied Geophysics, 174(3): 1133-1152. https://doi.org/10.1007/s00024$016-1448-\mathrm{Z}$

Chen, Z., Li, Y., LiU, Z., WANG, J., Zhou, X. and Du, J. (2018): Radon emission from soil gases in the active fault zones in the Capital of China and its environmental effects. Scientific Reports, 8(1): 1-12. https://doi.org/10.1038/s41598-018-35262-1 
Corbo-Camargo, F., Arzate-Flores, J. A., Álvarez-Bédar, R., Aranda-Gómez, J. J. and YUTSIS, V. (2013): Subduction of the rivera plate beneath the jalisco block as imaged by magnetotelluric data. Revista Mexicana de Ciencias Geologicas, 30(2): 268-281.

Emslie, S. D., McKenzie, A., Marti, L. J. and Santos, M. (2018): Recent occupation by Adélie Penguins (Pygoscelis adeliae) at Hope Bay and Seymour Island and the 'northern enigma' in the Antarctic Peninsula. Polar Biology, 41(1): 71-77. https://doi.org/10.1007/s00300-017-2170-8

ERKAN, K. (2008): A comparative overview of geophysical methods. Geodetic Science and Surveying, 3(488): 29-45.

FREUND, F. (2011): Pre-earthquake signals: Underlying physical processes. Journal of Asian Earth Sciences, 41(4-5): 383-400. https://doi.org/10.1016/j.jseaes.2010.03.009

LoBkovsKy, L. (2020): Seismogenic-triggering mechanism of gas emission activizations on the arctic shelf and associated phases of abrupt warming. Geosciences (Switzerland), 10(11): 1-10. https://doi.org/10.3390/geosciences 10110428

Montalti, D., Soave, G. E. (2002): The birds of Seymour Island, Antarctica. Ornitologia Neotropical, 13: 267-271.

Petraki, E., Nikolopoulos, D., Nomicos, C. D., Stonham, J., Cantzos, D., Yannakopoulos, P. and KotTou, S. (2015): Electromagnetic Pre-earthquake Precursors: Mechanisms, Data and Models-A Review. Journal of Earth Science \& Climatic Change, 06(01). https://doi.org/ 10.4172/2157-7617.1000250

RANGARAJAN, G. K., IYEMORI, T. (1997): Time variations of geomagnetic activity indices Kp and Ap: An update. Annales Geophysicae, 15(10): 1271-1290. https://doi.org/10.1007/s00585-997$1271-\mathrm{z}$

Simpson, F., BAHR, K. (2005): Practical magnetotellurics. In Practical Magnetotellurics (Vol. 9780521817, Issue February 2005). https://doi.org/10.1017/CBO9780511614095

Solano Fino, J. M. (2017): Correlación entre señales em y eventos sismológicos de la sabana de bogotá y alrededores para establecer la existencia de precursores sísmicos. Master Thesis, Universidad Nacional de Colombia, Bogota. https://repositorio.unal.edu.co/handle/unal/62292

Vargas, C. A., Caneva, A., Monsalve, H., Salcedo, E. and Mora, H. (2018): Geophysical networks in Colombia. Seismological Research Letters, 89(2A): 440-445. https://doi.org/ $10.1785 / 0220170168$

Vargas, C. A., Gomez, J. S., Gomez, J. J., Solano, J. M. and Caneva, A. (2021): Comment on seismic electric signals (SES) and earthquakes: A review of an updated VAN method and competing hypotheses for SES generation and earthquake triggering by Daniel S. Helman, physics of Earth and planetary interiors, 302 (2020). Physics of the Earth and Planetary Interiors, 313 (February), 2020-2022. https://doi.org/10.1016/j.pepi.2021.106676

VARotsos, P. A., SARLis, N. V. and SKORDAS, E. S. (2002): Long-range correlations in the electric signals that precede rupture. Physical Review E - Statistical, Nonlinear, and Soft Matter Physics, 66(1): 1-7. https://doi.org/10.1103/PhysRevE.66.011902

Varotsos, P. A., SARLis, N. V. and Skordas, E. S. (2006): On the recent advances in the study of seismic electric signals (VAN method). Physics and Chemistry of the Earth, 31(4-9): 189-197. https://doi.org/10.1016/j.pce.2006.02.008

Varotsos, P. A., Sarlis, N. V., Skordas, E. S. and Lazaridou, M. S. (2013): Seismic electric signals: An additional fact showing their physical interconnection with seismicity. Tectonophysics, 589: 116-125. https://doi.org/10.1016/j.tecto.2012.12.020

YUE, Z. Q. (2013): On nature of earthquakes with cause of compressed methane gas expansion and migration in crustal rocks. Poromechanics V-Proceedings of the 5th Biot Conference on Poromechanics, January, 507-516. https://doi.org/10.1061/9780784412992.060

\section{Web sources / Other sources}

[1] Ministerio de Relaciones Exteriores, comercio internacional y culto (2019). Dirección Nacional del Antártico.

https://www.cancilleria.gob.ar/es/iniciativas/dna/direccion-nacional-del-antartico 
J. M. SOLANO et al.

[2] Ministerio de Relaciones Exteriores, comercio internacional y culto (2018). Marambio. https://cancilleria.gob.ar/es/iniciativas/dna/antartida-argentina/bases/marambio

[3] Bartington Instruments (2015). Mag648 \& Mag649 Low Power Three-Axis Magnetic Field Sensors.

https://www.bartington.com/wp-content/uploads/pdfs/datasheets/Mag648_649_DS2298.pdf

[4] USGS (2021). USGS Earthquake Catalog.

https://earthquake.usgs.gov/earthquakes/search/

[5] National Oceanic and atmospheric Administration, N. (2021). Planetary K-index.

https://www.swpc.noaa.gov/products/planetary-k-index 